\title{
Subjective and Objective Assessment of Lateral videofluroscopy for patients with velopharyngeal valve incompetence
}

\author{
El-Adawy A. A.N. ${ }^{(a)}$, Gelaney A. E. ${ }^{(a)}$. Ahmed M. A. ${ }^{(c)}$ and Elsherbiny A. M.K ${ }^{\text {b), }}$
}

(a) Department of Phoniatrics, Sohag University.

(b) Department of Plastic Surgery, Sohag University

(c) Department of Otolaryngology, Sohag University.

\begin{abstract}
This study was designed to comparesubjective and objective assessment of lateral videoflruroscopyin patients with velopharyngeal valve incompetence. It is prospective randomized blind study of lateral videofluroscopic recordings whether subjectively by 3 different examiners or objectively. 19 consecutive patients with previously repaired cleft palates and symptomatic velopharyngeal incompetence (VPI). The results of this study no significant difference between subjective and objective evaluation of velar length $(\mathrm{P}$ value $=0.113)$ or velar thickness $(\mathrm{P}$ value $=0.752)$. So subjective assessment of velar length and thickness is effective in comparison with objective assessment and further research on a big sized sample is recommended.
\end{abstract}

Keywards: Hypernasalty, Velopharyngeal valve incompetence, lateral videofluroscopy.

\section{Introduction}

Videofluoroscopy is an imaging technique used to obtain real-time moving images of internalstructures. This is done through the use of a fluoroscope, which consists of an Xray source andfluorescent screen. A videofluoroscopic speech study is the use of moving images of thevelopharyngeal valve, along with simultaneous audio recordings, for the evaluation of velopharyngealfunction during speech (Dudas, et al., 2006; Lam et al., 2006; Smith and Kuehn, 2007).Videofluoroscopy can help the examiner assess both the anatomical and physiologicalabnormalities that are causing VPI. This information is important so that the optimal surgical orprosthetic treatment for the patient can be determined.

Multiviewvideofluoroscopy, including operation of a fluoroscopic system, interpretation and analysis of images recorded, have been extensively described by Skolnick and Cohn (1989).

ßSkolnick (1970) described four multiviewvideofluoroscopy views: lateral, frontal, Towne's and base view. There has been much discussions as regards to whether all these views are necessary.During the Lateral view the patient is positioned between the table and the fluoroscopic screen with the head in neutral position. The lateral view shows the anatomy of the soft palate and the posterior pharyngeal wall (PPW) in mid-sagittal plane, in the rest or breathing position and their movements during speech.

Changing the patient distance from the tube and the method of recording from the monitor whether directly or through a camera leads to changes in the dimensions of velopharyngeal valve that affects accuracy of the subjective parameters.

Standardized lateral videofluoroscopies were recorded usinga Viewmaster to minimize movement and rotation of the headand to standardize magnification

(Sommerlad et al., 1994). Ametal ring with a known internal diameter was included in thelateral videofluoroscopy 
recordings to measure the magnificationfactor, based on which absolute distances and lengthscould be calculated.

Sommerlad et al., (2002) designed a measuring system for objective analysis of velar anatomy and function. The

lateralvideofluroscopicrecordings were analyzed by amedical physicist who was unaware of the patients' identitiesand whether the recordings were made preoperatively or postoperatively.Measurements were made with the velum at rest in the nasal breathing position and at the point of maximum closure during production of the sound /i/, as previously described by Birch et al., (1994).It includes the assessment of velar length at rest and with maximum velar contraction, Velopharyngeal gap size at rest and with velar contraction, Velar angle, closure velocity, closure ratio and palatal extensibility.

The study was conducted to determine if there is significant difference between evaluations of lateral videofluroscopy whether subjectively or objectively.

\section{Material and method:}

This study is prospective cohort study conducted on a series of 38lateral videofluroscopic samples of 19 patients (each patient had 2 samples one before the operation and the other after the operation by 6 month) with VPI presented to the multidisciplinary cleft clinic at Sohag university hospital.The study is designed to exclude the patients who are 3 years or younger. The samples was randomly arranged then presented to the evaluator.

Assessment was done subjectively by Sohag assessment protocol of nasality that includes evaluation of

1- Velar length (2=long, $1=$ average, $0=$ short) and velar thickness ( $2=$ thick, $1=$ average, $0=$ thin $)$.
2- Degree of velar movement to contact the posterior pharyngeal wall $(0=$ no movement, $2=$ half the distance and $4=$ total closure).

3- Presence of adenoid pad $(0=a b s e n t$, $1=$ present).

4- Presence or absence of Passavant's ridge $(0=$ absent and $1=$ present $)$.

5- Tongue movement during speech $(0=$ normal movement and $1=$ posterior tongue motion assessing the velum).

6- Velar height during closure in relation to hard palate $(0=$ well below the level of the hard palate, $1=$ below the level of the hard palate, $2=$ at the level of the hard palate, $3=$ above the level of the hard palate and $4=$ well above the level of the hard palate).

Objective assessment of lateral Videofluoroscopy and assessment of Velar Function

Standardized lateral videofluoroscopies were recorded Objective evaluation of the lateral viewwas done by modification of Sommerlad et al., (2002)with using Image analysis system (digimizer version 3.7.2005-2010) medcalc softwere and using the hard palate length instead of the ring provided that the hard palate is intact.

It includes the following parameters (figure 1):

1. Resting Velar length (B-D): The mean distance of a curved line between $\mathrm{B}$ and $\mathrm{D}$ and parallel to the nasal velar border during velar rest.

2. Functional Velar length (B-E): The distance between the posterior nasal spine of the hard palate (B) to the velar knee at the point of maximum closure (E) with maximum velar contraction.

3. Remaining velar length (E_H): The distance between the velar knee at the point of maximum closure $(\mathrm{E})$ and the tip of the uvula $(\mathrm{H})$ with maximum velar contraction. 


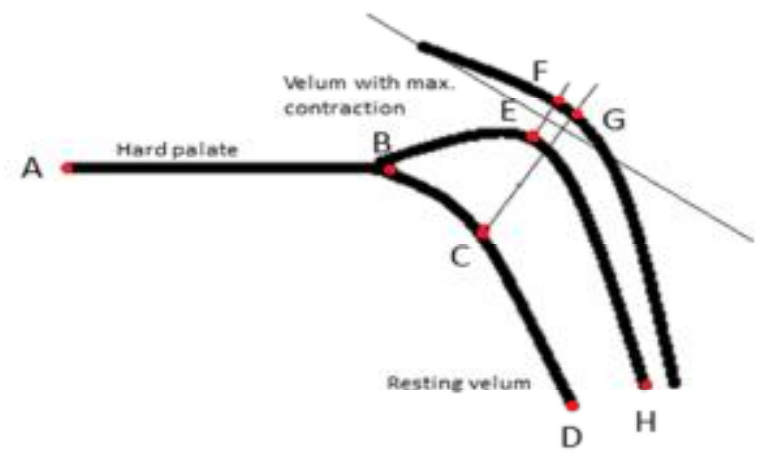

Figure (2): Diaphragmatic representation of the measures of soft palate and velopharyngeal valve during rest /i/ sound

$\mathrm{A}=$ Anterior nasal spine. $\quad \mathrm{B}=$ posterior nasal spine.

$\mathrm{C}=$ point in the soft palate nearest to the posterior pharyngeal wall (PPW).

$\mathrm{D}=$ the tip of the uvula during rest. $\quad \mathrm{E}=$ the point of the levator knee at maximum velar contraction.

$\mathrm{F}=$ point at the posterior pharyngeal wall (the point that meets the posterior pharyngeal wall by a line passing from $\mathrm{E}$ point to a line perpendicular to PPW and VPV).

$\mathrm{G}=$ point at the posterior pharyngeal wall (the point that meets the posterior pharyngeal wall by a line passing from $\mathrm{C}$ point to a line perpendicular to PPW and VPV)

$\mathrm{H}=$ Tip of the uvula with velar contraction /i/ sound.

4. Velar length on contraction (B-E+E-H): The sum of the distances of a line between $\mathrm{B}$ and levator knee $(\mathrm{E})$ and between $(\mathrm{E})$ to the tip of the uvula $(\mathrm{H})$ during maximum velar contraction.

5. Resting gap (C-G): The distance between a point on the dorsum of the soft palate nearest to the pharynx to the posterior pharyngeal wall using a perpendicular on it.

6. Gap with maximum contraction (E-F): The distance between levator knee of the palate and posterior pharyngeal wall using a perpendicular on it.

7. Resting and contracting velar thickness:The mean length of line passes between the nasal and the oral surfaces of the velum at the thickest portion during rest and contraction.

8. Closure ratio: gap size at rest (C-G) - gap size at maximum contraction (E-F) / gap size at rest (C-G) X100.

9. Palatal extensibility: palatal length on contraction $(B-E+E-H)$ - palatal length at rest (B-D)/palatal length at rest (B-D) X100.

\section{Statistics:}

Statistical analysis was done by using a statistics software package (SPSS for Windows 16.0) of the following:

- Descriptive statistical analysis of all subjective and objective paramaters of lateral videofluoroscopy results. 
- Comparing improvement of velar length and thickness before and after the operation using the Wilcoxon signed-rank test (two-tailed). The level of significance was set at $\mathrm{P}$ value $=.01$.

- Assessment of difference between subjective and objective measures of palatal length and thickness of lateral videofluroscopy measures was done using Mannwhitney $\mathrm{U}$ test. The level of significance was set at $\mathrm{P}$ value $=.01$.

\section{Results}

1- Descriptive analysis of subjective parameters

Subjective assessment of the parameters was done randomly by three different evaluators (table 1)

Table 1: Descriptive analysis of subjective parameters

\begin{tabular}{|l|l|l|}
\hline & Mean & SD \\
\hline Velar length & 1.075 & 0.55 \\
\hline Velar thickness & 1.05 & 0.48 \\
\hline Velar movement & 2.21 & 0.87 \\
\hline Velar height & 1.68 & 0.75 \\
\hline Passavant ridge & $\mathbf{0 . 2 5}$ & $\mathbf{0 . 5 2}$ \\
\hline Adeniodenlargment & $\mathbf{0 . 3}$ & $\mathbf{0 . 8 4}$ \\
\hline Tongue assisted movement & $\mathbf{0 . 9 8}$ & $\mathbf{0 . 6 7}$ \\
\hline
\end{tabular}

2- Descriptive analysis of objective parameters:

Descriptive parameters of the velopharyngeal valve were measured for 38 samples using digimizer version 3.7.2005-2010(table 2).

Table 2: Descriptive analysis of objective parameters

\begin{tabular}{|l|l|l|}
\hline & mean & SD \\
\hline Resting palatal length & $\mathbf{0 . 8 5}$ & $\mathbf{0 . 2 1}$ \\
\hline Total length in /i/ sound & $\mathbf{0 . 9 2}$ & $\mathbf{0 . 2 3}$ \\
\hline Functional velar Length & $\mathbf{0 . 4 8}$ & $\mathbf{0 . 1 4}$ \\
\hline Remaining velar length & $\mathbf{0 . 4 3}$ & $\mathbf{0 . 1 4}$ \\
\hline Resting velar thickness & $\mathbf{0 . 2 7}$ & $\mathbf{0 . 0 8}$ \\
\hline Velar thickness with /i/ sound & $\mathbf{0 . 2 8}$ & $\mathbf{0 . 0 9}$ \\
\hline Resting gap & $\mathbf{0 . 2 5}$ & $\mathbf{0 . 0 9}$ \\
\hline Gap with /i/ sound & $\mathbf{0 . 1 4}$ & $\mathbf{0 . 0 9}$ \\
\hline Velar angle & $\mathbf{1 2 2 . 3 6}$ degree & $\mathbf{1 7 . 1 2}$ \\
\hline Closure ratio & $\mathbf{0 . 4 6}$ & $\mathbf{0 . 2 9}$ \\
\hline Palatal extensibility & $\mathbf{0 . 1 4}$ & $\mathbf{3 2 . 7 6}$ \\
\hline
\end{tabular}

3- Subjective velar change with the operation

There is significant improvement of all parameters measured subjectively (table 3)

Table 3:Subjective velar change with the operation

\begin{tabular}{|c|c|c|c|}
\hline Parameters & Pre-operative & $\begin{array}{l}6 \text { months after the } \\
\text { operation }\end{array}$ & \\
\hline & (Mean/+SD) & (Mean/+SD) & P value \\
\hline VelarLength & $0.37 \pm 0.68$ & $1.78 \pm 0.41$ & 0.000 \\
\hline Velar Thickness & $0.42 \pm 0.50$ & $1.68 \pm 0.47$ & 0.000 \\
\hline Velar Movement & $1.68+0.74$ & $2.7368+0.99$ & 0.008 \\
\hline Velar Height & $1.36+0.68$ & $2.0000+0.81$ & 0.005 \\
\hline
\end{tabular}




\section{4-Changes in the objective velar parameters with the operation:}

There is significant improvement of all parameters measured subjectively except palatal extensibility (table 4).

Table 4: Changes in the objective velar parameters with the operation

\begin{tabular}{|l|l|l|l|}
\hline & $\begin{array}{l}\text { Pre-operative } \\
(\text { Mean/+SD) }\end{array}$ & $\begin{array}{l}\text { 6 month } \\
\text { postoperative } \\
(\text { Mean/+SD })\end{array}$ & P value \\
\hline Resting palatal length & $\mathbf{0 . 6 8} \pm \mathbf{0 . 2 1}$ & $\mathbf{1 . 0 1} \pm \mathbf{0 . 2 2}$ & $\mathbf{0 . 0 0 1}$ \\
\hline Total length in /i/ sound & $\mathbf{0 . 7 1} \pm \mathbf{0 . 2 0}$ & $\mathbf{1 . 1 3} \pm \mathbf{0 . 2 5}$ & $\mathbf{0 . 0 0 1}$ \\
\hline Functional velar Length & $\mathbf{0 . 3 6} \pm \mathbf{0 . 1 1}$ & $\mathbf{0 . 6 0} \pm \mathbf{0 . 1 6}$ & $\mathbf{0 . 0 0 1}$ \\
\hline Remaining velar length & $\mathbf{0 . 3 4} \pm \mathbf{0 . 1 1}$ & $\mathbf{0 . 5 2} \pm \mathbf{0 . 1 6}$ & $\mathbf{0 . 0 0 8}$ \\
\hline Resting velar thickness & $\mathbf{0 . 1 8} \pm \mathbf{0 . 0 7}$ & $\mathbf{0 . 3 5} \pm \mathbf{0 . 0 9}$ & $\mathbf{0 . 0 0 1}$ \\
\hline Velar thickness with /i/ sound & $\mathbf{0 . 2 0} \pm \mathbf{0 . 0 7}$ & $\mathbf{0 . 3 9} \pm \mathbf{0 . 1 1}$ & $\mathbf{0 . 0 0 1}$ \\
\hline Resting gap & $\mathbf{0 . 2 8} \pm \mathbf{0 . 0 9}$ & $\mathbf{0 . 2 1} \pm \mathbf{0 . 0 9}$ & $\mathbf{0 . 0 1 2}$ \\
\hline Gap with /i/ sound & $\mathbf{0 . 2 1} \pm \mathbf{0 . 1 2}$ & $\mathbf{0 . 0 7} \pm \mathbf{0 . 0 7}$ & $\mathbf{0 . 0 0 1}$ \\
\hline Closure ratio & $\mathbf{0 . 3 2} \pm \mathbf{0 . 2 3}$ & $\mathbf{0 . 7 1} \pm \mathbf{0 . 3 5}$ & $\mathbf{0 . 0 0 3}$ \\
\hline Palatal extensibilty & $\mathbf{1 6 . 6 \pm 6 2 . 9 6}$ & $\mathbf{1 2 . 9 4} \pm 19.73$ & $\mathbf{0 . 5 7 0}$ \\
\hline
\end{tabular}

\section{5- Comparing Subjective and objective velar Lengths and Velar thickness}

There is no statistically significant difference between measuring the palatal length subjectively or objectively (0.113). The mean length by subjective assessment was $0.68 \pm 0.21$ while by objective assessment was $0.47 \pm 0.74$.

As regard velar thickness there is no statistically significant difference between measuring the palatal length subjectively or objectively (0.752). The mean length by subjective assessment was $0.35 \pm 0.09$ while by objective assessment was $0.53 \pm 0.52$ (table 5).

Table (5): subjective and objective assessment of the palateusing Mann-whitney $U$ test. The level of significance was set at $\mathrm{P}$ value $=.01$

\begin{tabular}{|l|l|l|l|}
\hline & $\begin{array}{l}\text { Subjective assessment } \\
(\text { mean } \pm \text { SD })\end{array}$ & $\begin{array}{l}\text { Objective assessment } \\
(\text { mean } \pm \text { SD })\end{array}$ & P value \\
\hline Velar Length & $\mathbf{0 . 6 8} \pm \mathbf{0 . 2 1}$ & $\mathbf{0 . 4 7} \pm \mathbf{0 . 7 4}$ & $\mathbf{0 . 1 1 3}$ \\
\hline Velar thickness & $\mathbf{0 . 3 5} \pm \mathbf{0 . 0 9}$ & $\mathbf{0 . 5 3} \pm \mathbf{0 . 5 2}$ & $\mathbf{0 . 7 5 2}$ \\
\hline
\end{tabular}

\section{Discussion}

Sommerlad et al., (1994) stated lateral videofluoroscopy providesthe most accurate method of measuring velar movementand that the use of a computerized method ofmeasurement provides a reproducible objective means of quantifying such movement.

All patients in the study underwent the protocol of assessment of the Phoniatrics unit of Sohag University Hospital. The patients were assessed as regard velopharyngeal valve functions by lateral videofluroscopy randomly. This assessment was done subjectively and objectivelyusing Image analysis system (digimizer version 3.7.2005-
2010) medcalc softwere. We didn't use a measurement caliper during recording of the fluoroscopy video sequences. So, to standardize the measurements, we divided all values by the length of the hard palate assuming that the hard palate length is not changing.

The study is designed to exclude the patients who are 3 years or younger as it is difficult to assess resonance, speech and velopharyngeal valve functions(Kummer, 2005).

Modification of Sommerlad et al., (2002) lateral videofluoscopy objective assessment was done by changing 
some measures like resting gap as sommerlad et al., (2002) descibed it as the distance between the levator genu and posterior pharyngeal wall while in the modification it is descibed asthe distance between a point on the dorsum of the soft palate nearest to the pharynx to the posterior pharyngeal wall using a perpendicular on it. This change was done as it is difficult to accurately detect the site that represents the velar knee at rest.

The International Working Group proposed the Standardization method for reporting multiviewvideofluorosocopy and nasopharyngoscopy(Golding-Kushner et al., 1990). This involves bothqualitative and quantitative or ratiometric measurements. For example, in the lateral view, velarmovement towards the posterior pharyngeal wall is rated using a ratiometric scoring system from 0.0 to 1.0, where 1.0indicates complete closure. Parameters such as palatal length, pharyngeal depth and estimation of gapsize are excluded as the authors stated that these are not standardized and could not be assessed.However, the reliability of quantitative measurements of videofluoroscopy remains a continuingissue. Several authors reported applying the Golding-Kushner scale (Armour et al., 2005; Lam et al., 2006), a 'ratio' method (Ysunza et al., 1992), a 'percentageclosure' method (Dudas et al., 2006), or a fivepoint proportional scale (Henningsson and Isberg, 1991) to analysevideofluoroscopic data, but have failed to report any inter-rater reliability measures.Using subjective rating scales, Liedman-Boshko et al., (2005) reported a mean exact interobserveragreement of $65 \%$ when assessing closure activity from the frontal view, whilst Pereira et al., (2008)reported only a fair to moderate inter-rater reliability when assessing degree ofvelopharyngeal closure from lateral view.A measurement system that enables absolute and relative measures of velopharyngeal function usingspecialized software has been described with very high inter-rater agreement (Birch et al., 1994).

The operation that was done is a lengthening operation of the palate and the objective measures results showed increase in the velar length, thickness, closure ratio due to lengthening effect of the operation and this in turn leads to decrease in gap.

These data are aligned with subjective results that showed improvement in velar length, thickness, height and movement.

This study showed importance of subjective measures assessment especially velar length and thickness that are valuable for choosing appropriate operation as described by the surgeon. There are also some data were not measured objectively like posterior tongue movement is assessing velar movement that are important for phoniatricans for selecting speech therapy maneuver.

Objective assessment of velar function describes more accurate data that may be used for research as when measuring velar length, thickness, gap, extensibility and closure ratio. The surgeon may detect the needed amount of increase of length and amount of pushing the genu posteriorly to get the most accurate results.

In our study no statically significant difference detected between measuring the palatal length and thickness whether subjectively or objectively.

Subjective assessment is rapid and easy tool for assessment of VPI and choosing the appropriate line of management while objective assessment is more accurate and can be used for research. 


\section{References}

1. Armour, A., Fischbach, S., Klaiman, P. and Fisher, D. (2005): Does velopharyngeal closure patternaffect the success of pharyngeal flap pharyngoplasty? Plastic and Reconstructuve Surgery, 115, 45-52.

2. Birch, M., Sommerlad, B.C. and Bhatt, A. (1994): Image analysis of lateral velopharyngeal closure inrepaired cleft palates and normal palates. British Journal of Plastic Surgery, 47, 400-405.

3. David, D.J. and Bagnall, A.D. (1990): Velopharyngeal incompetence. In: McCarthy; G Joseph; (Eds.), Plastic Surgery. WB Sunders Company, Philadelphia, 4: 2903-2921.

4. Dudas, J. R., Deleyiannis, F. W., Ford, M. D., Jiang, S., andLosee, J. E. (2006): Diagnosis and treatment of velopharyngeal insufficiency:Clinical utility of speech evaluation and videofluoroscopy. Annals of Plastic Surgery, 56(5), 511-517; Discussion 517.

5. Golding-Kushner, K. J., Argamaso, R. V., Cotton, R. T., Grames, L.M., Henningsson, G., Jones, D. L. and Karnell, M. P. (1990): Standardization for the reporting ofnasopharyngoscopy and multiviewvideofluoroscopy: A report from an International Working Group. Cleft Palate Journal, 27 (4), 337-347; Discussion 347-348.

6. Henningsson, G.E. and Isberg, A.M. (1986): Velopharyngeal movement patterns in patients alternatingbetween oral and glottal articulation: a clinical and cineradiographical study. The Cleft Palate Journal, 23 (1), 1-9.

7. Hens, G., Sell D., Pinkstone, M., Birch, M.J., Hay, N., Sommerlad, B.C. and Kangesu, L. (2012): Palate Lengthening

BuccinatorMyomucosal Flaps for Velopharyngeal Insufficiency.Cleft Palate-Craniofacial Journal, Vol. 50 No. 5.

8. Kummer, A .W. (2005): Cleft palate and craniofatial anomalies: The effects on speech and resonance. Cincinnata, Ohio: WB Saunders, 401-424.
9. Lam, D. J., Starr, J. R., Perkins, J. A., Lewis, C. W., Eblen, L. E., Dunlap, J., and Sie, K. C. (2006): A comparison of nasendoscopy and multiviewvideofluoroscopy in assessing velopharyngeal insufficiency. Otolaryngology- Head and Neck Surgery, 134(3), 394-402.

10.Liedman-Boshko, J., Lohmander, A. and Persson, C. (2005): Perceptual analysis of speech and the activity in the lateral pharyngeal walls before and after velopharyngeal flap surgery. Scandinavian Journal of Plastic and Reconstructive and Hand Surgery, 39, 22-32.

11.Pereira, V., Sell, D. and Ponniah, A. (2008):Midface osteotomy versus distraction: the effect on speech, nasality and velopharyngeal function in craniofacial dysostosis. Cleft PalateCraniofacial Journal, 45, 353-363.

12. Skolnick, M.L. (1970): Videofluoroscopic examination of the velopharyngeal portal during phonation in lateral and base projections-a new technique for studying the mechanics of closure. Cleft Palate Journal, 7, 803816.

13. Smith, B. E., and Kuehn, D. P. (2007): Speechevaluation of velopharyngeal dysfunction. The Journal of Craniofacial Surgery, 18(2),251-260.

14. Sommerlad, B.C., Mehendale, F.V., Birch, M.J., Sell, D., Hattee, C. and Harland, K. (2002): Palate re-repair revisited. Cleft Palate Craniofac J.39:295-307.

15. Sommerlad, B.C., Rowland, N. and Harland, K. (1994): Lateral videofluoroscopy: a modification to aid in velopharyngeal assessment and measurement. Cleft Palate Craniofacial Journal, 31, 134- 135.

16. Ysunza, A., Pamplona, C. and Toledo, E. (1992): Change in velopharyngealvalving after speechtherapy in cleft palate patients. A videonasopharyngoscopic and multiview videofluoroscopic study.International Journal of Pediatric Otorhinolaryngology, 24, 45-54. 
SOHAG MEDICAL JOURNAL

Vol. 21 No.2 July 2017
Subjective and Objective Assessment Ahmed El sayed Gelaney.et al 